\title{
Performance Improvement of Hopper Cooling System on Traditional Fishing Boats Due to Excessive Cooling
}

\author{
Eddy Setyo Koenhardono ${ }^{1)^{*}}$ ) \\ 1) Department of Marine System Engineering, Faculty of Marine Technology, Institute of Technology Sepuluh Nopember, Surabaya 60111, \\ Indonesia \\ ") Corresponding Author : eddy-koen@its.ac.id
}

\section{Article Info}

Abstract

\section{Keywords:}

Seawater Cooling System,

Hopper System,

Fishing Boat Motorization

Program,

Traditional Fishing Boat,

Excessive Cooling,

Fuel Saving

\section{Article history:}

Received: 13/04/20

Last revised: 01/06/20

Accepted: 03/06/20

Available online: 23/06/20

DOI:

https://doi.org/10.14710/kapal. v17i2.29496

\begin{abstract}
The engine cooling system that drives traditional fishing boats uses a hopper cooler type system that experiences excessive cooling. Ideally, the temperature of the cooling water in the hopper should be approximately $70-80^{\circ} \mathrm{C}$. The fact, it is only $42^{\circ} \mathrm{C}$, thus reducing the effective power generated by the engine. This excessive cooling may cause an increase in fuel consumption and emissions. One method to reduce excessive cooling is to increase the temperature of the cooling media in the hopper. The author has conducted a simple experiment on a traditional fishing boat in Kenjeran, Surabaya, by installing a valve to control the flow of seawater entering the hopper. However, the use of seawater as a cooling medium has a maximum operating temperature limitation, so there is no precipitation of salt and lime, which is $50^{\circ} \mathrm{C}$. At this temperature, the benefits are not large, only an increase in speed of $4.4 \%$ and a fuel reduction of $4.3 \%$. Therefore, the existing seawater cooling system must be modified to an indirect seawater cooling system to get optimum performance improvement. The remodification allows the temperature of the freshwater in the hopper to be maintained at $80^{\circ} \mathrm{C}$, so that the speed of the fishing boat may increase by $14 \%$, with a fuel savings of $12.3 \%$.
\end{abstract}

Copyright (C 2020 KAPAL : Jurnal Ilmu Pengetahuan dan Teknologi Kelautan. This is an open access article under the CC BY-SA license (https://creativecommons.org/licenses/by-sa/4.0/).

\section{Introduction}

Fishing in the sea is one method of producing highly nutritious food sources that require enormous energy in the world today [1]. In Indonesia, the fishing boat motorization program in the 80s made the fishing community depend heavily on fuel availability. Another consequence of this program is that it resulted in over-fishing in many fishing grounds in Indonesia.

The fishing boat motorization program was implemented with the aim of increasing the amount of fish being caught. However, it brought a consequence of not giving a sufficient amount of knowledge on motor diesel towards the fishermen. The results, the use of diesel engines as boat propulsion was less efficient, which produces fuel waste and high emissions production, where one of them is the occurrence of excessive cooling.

The cooling water system on the diesel engine, which drives the traditional fishing boat, has the primary function of keeping the engine temperature within the allowable limit. Therefore, it generates maximum engine performance during its operation [2]. There are three basic types of cooling systems commonly used by boat engines, which are direct cooling systems, keel cooling systems, and heat exchanger cooling systems [3].

Direct cooling systems are much simpler and cheaper than indirect cooling systems as seawater only flows through the engine. Examples of these include keel cooling systems and heat exchangers cooling systems. However, seawater has corrosive properties resulting in the deposition of salt in the cooling water chamber [4], [5]. Therefore, it is necessary to operate the engine at a cool enough temperature since sea salt begins to precipitate from water at $50^{\circ} \mathrm{C}[3]$.

However, the lower temperature of the coolant brings a consequence, which is increases the heat transfer and reduces the metal temperature of the cylinder head, cylinder, and piston. As a result, the average temperature and gas pressure reduces, the loss in friction increases and the work per cycle transferred to the piston reduces [6]. Besides, lower cooling water temperatures bring impacts towards emissions of nitrogen oxides, carbon monoxide, carbon dioxide, and unburned 
hydrocarbons [6], [7]. Other advantages of increasing the coolant temperature include reducing the mass flow rate of fuel consumption and reducing power losses in the cooling system [6].

Due to the weaknesses and limitations of using direct cooling systems that using seawater as a media, in modern ships, the use of direct cooling systems has been replaced by indirect cooling systems in the form of box coolers and heat exchangers. There are two systems in an indirect cooling system. Firstly, freshwater is used as a medium for the engine cooling system. Secondly, freshwater is then consequently cooled by seawater through a box cooler or a heat exchanger. The temperature of freshwater that comes out from engine cooling is maintained at $71^{\circ} \mathrm{C}-80^{\circ} \mathrm{C}$ using a three-way valve [8].

To meet the IMO regulations for reducing $\mathrm{CO}_{2}$ gas emissions, that the aim of producing greener ships, various efforts have been made to improve the power plant system's performance. One of them is the use of high-temperature cooling methods. Implementation of this method can only be carried out on closed type liquid cooling systems where the fluid pressure in the cooling system has a pressure above the ambient pressure. This condition enables the coolant fluid to reach a higher temperature without boiling []ㅡ, [10]. At the experimental stage, the experiment is carried out until the coolant temperature in the cooling jacket reaches $204^{\circ} \mathrm{C}$, where the engine shows stable performance [ 10$]$.

However, the cooling system used in Indonesian traditional fishing boats is a direct cooling system with seawater, using a modified hopper method. Indeed, the hopper cooling system is the simplest water-cooling system, as shown in Figure 1 . The cylinder wall of the combustion chamber is inside the hopper, enabling the heat in the wall to be immediately cooled. High load operation for a long time causes the water in the hopper to boil and evaporate. This condition results in reduced water; thus, it is necessary to replenish it through the open section above.

The hopper cooling system on traditional fishing boats has been modified, so that cooling water flows continuously into the hopper and exits through the cooling water outlet, which then converts the cooling medium from freshwater to seawater. The seawater can flow into the hopper through a bent pipe behind the propeller as it is pushed by the propeller (Figure 2). Seawater can enter the hopper where it receives a thrust from the propeller rotation, eliminating the need for a pump. The flow of seawater entering the hopper is proportional to the thrust generated by the propeller.

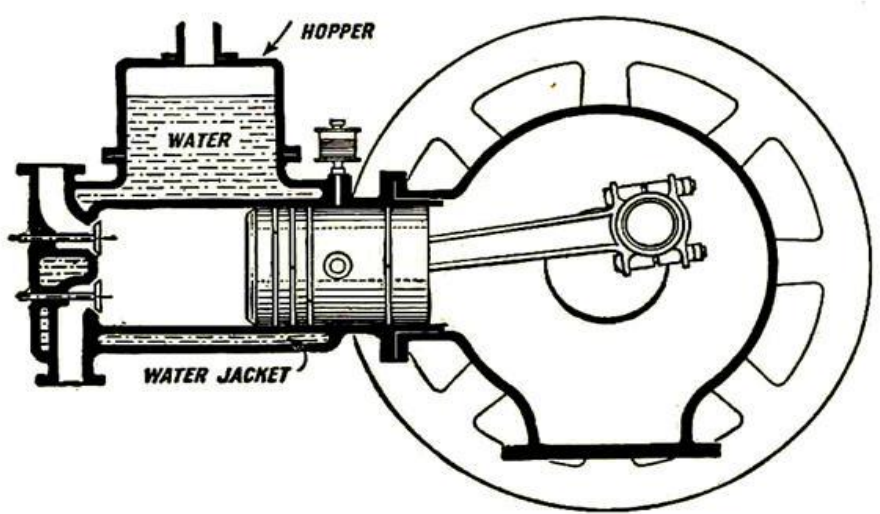

Figure 1. Hopper Cooling System Construction [11]

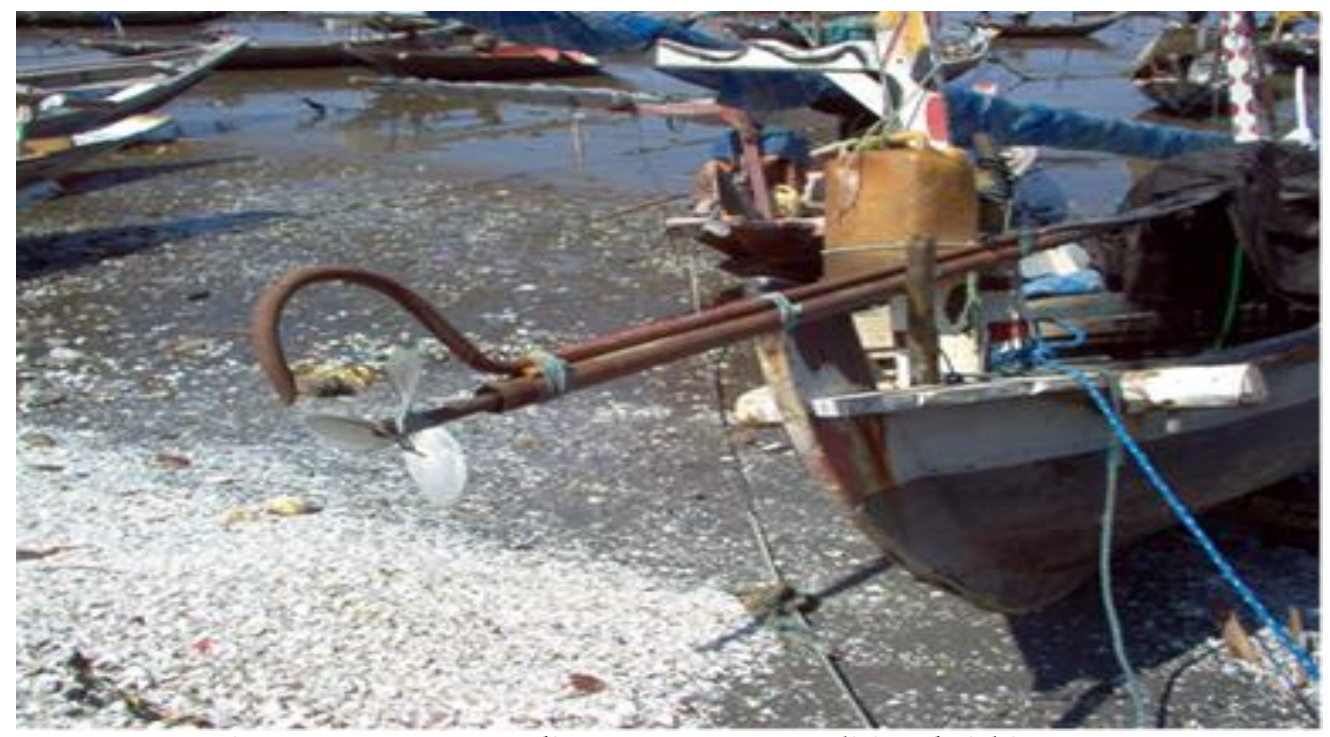

Figure 2. Seawater Cooling System on a Traditional Fishing Boat

Based on the real conditions on a traditional fishing boat, seawater that flows out of the hopper has a temperature of $42^{\circ} \mathrm{C}$. Due to the low cooling water temperature, the engine receives excessive cooling. Therefore, this paper aims to examine the hopper type cooling system on the existing traditional fishing boats, and finding the solutions in overcoming the excessive cooling that occurs. 


\section{Methods}

The research on the hopper type cooling system on the traditional fishing boat engine was carried out in the fishing community in Kenjeran Area, Surabaya, where the boat and the engine technical data used as the object of research are as shown in Table 1 and Table 2.

Table 1. Principal Dimension of The Boat

\begin{tabular}{ll}
\hline Parameters & Value \\
\hline Length & $8.00 \mathrm{~m}$ \\
Breadth & $2.00 \mathrm{~m}$ \\
Height & $1.00 \mathrm{~m}$ \\
Draft & $0.60 \mathrm{~m}$ \\
\hline
\end{tabular}

Table 2. Engine Data

\begin{tabular}{ll}
\hline Parameters & Value \\
\hline Merk & Dong Feng \\
Type & RD 85 NT \\
Power/RPM & 7,5 HP/2200 RPM \\
Cylinder & 1(Horisontal type $)$ \\
SFOC & 195 gr/HP.hours \\
Cooling system & open with hopper \\
Combustion & direct injection \\
Weight & 83 kg \\
\hline
\end{tabular}

\subsection{Existing Conditions Experiments}

The aim of performing the existing conditions experiment is to find out the fishing boat's initial performance on a daily operational condition. The cooling system experiment on a fishing boat is in Figure 3. The experiment was carried out by operating a diesel motor in four operational conditions based on four throttle positions, which are $25 \%, 50 \%, 75 \%$, and 100\%. Observations were made every 5 minutes at each throttle position. The observational data measured are the temperature of seawater flowing in and out of the hopper being read by the bimetal thermometer and the seawater flow rate obtained by using a $1000 \mathrm{ml}$ glass measuring cup and timer.

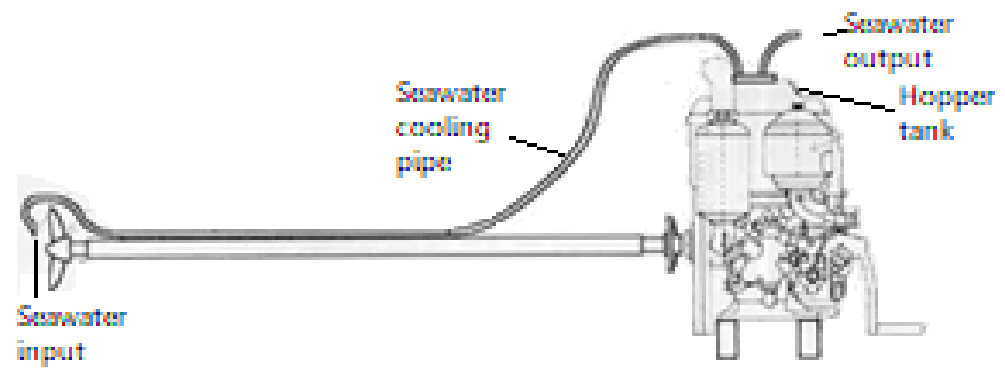

(a) Existing Hopper Seawater Cooling System

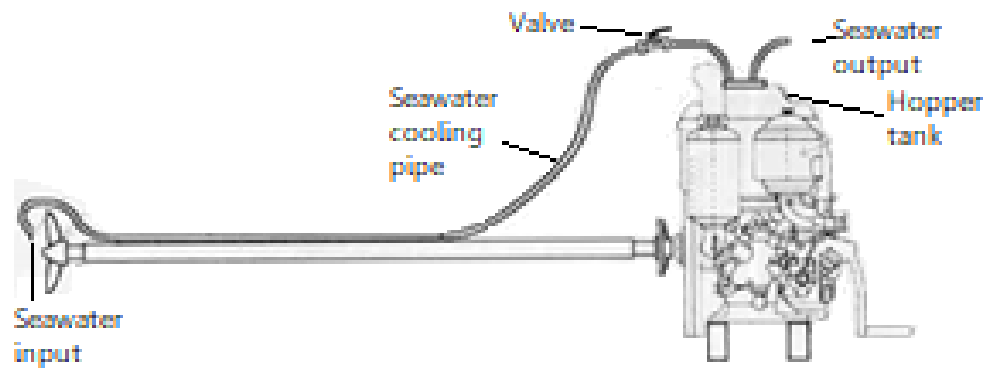

(b) Hopper Seawater Cooling System With Valve

Figure 3. Hopper Seawater Cooling System on Traditional Fishing Boat

\subsection{Experiment with Adding Valves}

In this experiment, a valve is added to the seawater flow before entering the hopper, as shown in Figure 3(b). In this second experiment, the engine throttle position is set to $100 \%$ or assumed to be at full load. Adjustments are made to the valve position opening for four positions, which are fully open (100\%), $75 \%$ open position, $50 \%$ open position, and $25 \%$ open position. The data recorded includes the speed of the boat using GPS, the seawater's temperature flowing in and out of the hopper, and the seawater flow rate. 


\section{Results and Discussion}

\subsection{The Analysis of Seawater Cooling Systems on Traditional Fish Boat Engines}

In the 70s, the Indonesian Government implemented a motorization program on traditional fishing boats. On the one hand, the program has succeeded in increasing the amount of fish being caught by the traditional fishermen; on the other hand, this bought a consequence in overfishing conditions. It also resulted in a further effect where fishers had to rely heavily on fluctuations in fuel prices. An increase in fuel prices will derive an increase in operational costs, while at the same time, the amount of fish being caught has been decreased. This condition brings a significant negative impact on the welfare of traditional fishers.

At the time when this paper was being written, no previous researches on the modification of the diesel motor cooling system on traditional fishing boats were found. Hence on this basis, the researchers will focus on analyzing the impact of modifications to the seawater cooling system on a diesel motor as a driving force for traditional fishing boats. In general, a closed cooling system is a system which comprises of a diesel motor equipped with a hopper, where the engine cylinder block is surrounded by seawater [12], as seen in Figure 4. When the diesel motor is being operated, the seawater in the hopper boils, causing the seawater to evaporate, which at the same time causes the volume of seawater to decrease. Therefore, it is necessary to replenish the seawater in the hopper, as seen in Figure 4. When the diesel motor is being operated, the seawater in the hopper boils, causing the seawater to evaporate, which at the same time causes the volume of seawater to decrease. Therefore, it is necessary to replenish the sea water in the hopper.

As a result of the change from a closed cooling system to an open/direct cooling system, refilling is unnecessary. However, due to a lack of knowledge about diesel engines, this modification has led to greater power absorption in the cooling system. Technically, due to the risk of deposition of salt and lime in the direct seawater cooling system, the operating temperature of the direct cooling system $\left(50^{\circ} \mathrm{C}\right)$ is maintained lower compared to temperature in the indirect cooling system, which reaches $80^{\circ} \mathrm{C}$. The greater power absorption is due to excessive cooling. The heat absorbed by the cooling water media can be obtained using the following heat transfer equation, as shown in Eq. 1 [13]:

$$
\begin{aligned}
Q_{c o o l} & =m_{s w} \cdot c_{s w}\left(T_{\text {out }}-T_{\text {in }}\right) \\
& =V_{\text {sw }} \cdot \rho_{\text {sw }} \cdot c_{\text {se }}\left(T_{\text {out }}-T_{\text {in }}\right)
\end{aligned}
$$

where $\mathrm{Q}_{\text {cool }}=$ heat absorbed by sea water cooling $(\mathrm{kcal} / \mathrm{h}), \mathrm{m}_{\mathrm{sw}}=$ seawater mass flow rate $(\mathrm{kg} / \mathrm{h}), \mathrm{V}_{\mathrm{sw}}=$ seawater flow rate $\left(\mathrm{m}^{3} / \mathrm{h}\right), \rho_{\mathrm{sw}}=$ seawater density $=1025 \mathrm{~kg} / \mathrm{m}^{3}, \mathrm{c}_{\mathrm{sw}}=$ specific heat of seawater $=0,94 \mathrm{kcal} / \mathrm{kg} .{ }^{\circ} \mathrm{C}, \mathrm{T}_{\text {out }}=$ temperature of seawater outlet $\left({ }^{\circ} \mathrm{C}\right), \mathrm{T}_{\text {in }}=$ temperature of seawater inlet $\left({ }^{\circ} \mathrm{C}\right)$.

In order to prove the existence of excessive cooling, an experiment was carried out by analyzing the conditions that occurred in traditional fishing boats. The test was carried out at Kenjeran beach, Surabaya, under the same condition that was repeated up to 3 times. Loading variations on the diesel motor is done by setting the throttle position at $25 \%, 50 \%, 75 \%$, and $100 \%$. The results of the experiment are shown in Table 3.

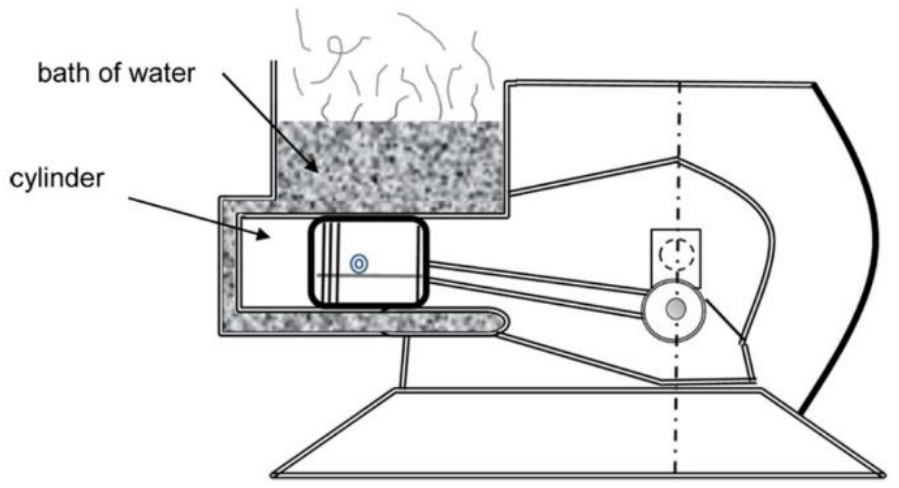

Figure 4. Evaporative Cooling System in which the Engine Cylinder Block Is Surrounded by a Bath of Water (Hopper)[12]

Table 3. Results Of Cooling System Experiments On Traditional Fishing Boats In The Kenjeran, Surabaya

\begin{tabular}{llllll}
\hline Exp. & Throttle & $\mathbf{2 5 \%}$ & $\mathbf{5 0} \%$ & $\mathbf{7 5 \%}$ & $\mathbf{1 0 0} \%$ \\
\hline 1 & $\mathrm{~T}_{\text {in }}\left({ }^{\circ} \mathrm{C}\right)$ & 29 & 29 & 29 & 29 \\
& $\mathrm{~T}_{\text {out }}\left({ }^{\circ} \mathrm{C}\right)$ & - & 41 & 41.5 & 42 \\
& $\mathrm{~V}_{\text {sw }}\left(\mathrm{m}^{3} / \mathrm{h}\right)$ & - & $7.8 \times 10^{-5}$ & $8 \times 10^{-5}$ & $9.25 \times 10^{-5}$ \\
& $\mathrm{Q}_{\text {cool }}(\mathrm{kcal} / \mathrm{h})$ & - & $3,246.6$ & 3468,6 & 4171 \\
2 & $\mathrm{~T}_{\text {in }}\left({ }^{\circ} \mathrm{C}\right)$ & 29 & 29 & 29 & 29 \\
& $\mathrm{~T}_{\text {out }}\left({ }^{\circ} \mathrm{C}\right)$ & - & 41 & 42 & 42 \\
& $\mathrm{~V}_{\text {sw }}\left(\mathrm{m}^{3} / \mathrm{h}\right)$ & - & $7.86 \times 10^{-5}$ & $8.14 \times 10^{-5}$ & $9.24 \times 10^{-5}$ \\
& $\mathrm{Q}_{\text {cool }}(\mathrm{kcal} / \mathrm{h})$ & & $3,271.6$ & $3,670.5$ & $4,166.5$ \\
3 & $\mathrm{~T}_{\text {in }}\left({ }^{\circ} \mathrm{C}\right)$ & 29 & 29 & 29 & 29 \\
& $\mathrm{~T}_{\text {out }}\left({ }^{\circ} \mathrm{C}\right)$ & - & 41 & 42 & 42 \\
& $\mathrm{~V}_{\text {sw }}\left(\mathrm{m}^{3} / \mathrm{h}\right)$ & - & $7.89 \times 10^{-5}$ & $8.13 \times 10^{-5}$ & $9.24 \times 10^{-5}$ \\
& $\mathrm{Q}_{\text {cool }}(\mathrm{kcal} / \mathrm{h})$ & - & $3,284.1$ & 3.666 & $4,166.5$ \\
\hline
\end{tabular}




\begin{tabular}{llllll}
\hline Average & $\mathrm{T}_{\text {in }}\left({ }^{\circ} \mathrm{C}\right)$ & 29 & 29 & 29 & 29 \\
& $\mathrm{~T}_{\text {out }}\left({ }^{\circ} \mathrm{C}\right)$ & - & 41 & 41,83 & 42 \\
& $\mathrm{~V}_{\text {sw }}\left(\mathrm{m}^{3} / \mathrm{h}\right)$ & - & $7,86.10^{-5}$ & $8,14.10^{-5}$ & $9,24.10^{-5}$ \\
& $\mathrm{Q}_{\text {cool }}(\mathrm{kcal} / \mathrm{h})$ & - & 3267,4 & 3601,7 & 4168 \\
\hline
\end{tabular}

Based on the experimental results in Table 3, the temperature of seawater in the engine cooling system used by traditional fishermen is too low. At the $100 \%$ throttle or maximum power, the temperature of outlet seawater is only $420 \mathrm{C}$, while the maximum temperature can be up to $50 \mathrm{oC}$. This condition caused excessive heat absorption by the cooling system. Another consequence it brings is that it generates an occurrence of cracks in the cylinder block, as experienced by the fishing community in Weru, Paciran, Lamongan. Absorption of large heat energy through the cooling system reduces the energy needed to drive the propeller, which in turn reduces the fishing boat speed. Summarily, excessive cooling is one of the sources of increased fuel consumption.

\subsection{The Analysis of Valve Installation Impact}

In the second experiment, a valve was installed at the end of the cooling pipe (at the inlet of the hopper). The experiments were carried out by adjusting valve openings (100\%,75\%, 50\%, and 25\%) with the condition of the diesel engine being positioned at $100 \%$. The experiment was repeated twice on each valve openings. The results of the second experiment can be seen in Table 4.

Table 4. Experimental Results on Both Cooling Systems

\begin{tabular}{clllll}
\hline \multirow{2}{*}{ Exp. } & \multirow{2}{*}{ Measurement } & \multicolumn{4}{c}{ Position of opening valve } \\
\cline { 3 - 6 } & & $\mathbf{1 0 0 \%}$ & $\mathbf{7 5 \%}$ & $\mathbf{5 0 \%}$ & $\mathbf{2 5 \%}$ \\
\hline 1 & $\mathrm{~T}_{\text {in }}\left({ }^{\circ} \mathrm{C}\right)$ & 29 & 29 & 29 & 29 \\
& $\mathrm{~T}_{\text {out }}\left({ }^{\circ} \mathrm{C}\right)$ & 43 & 49 & 55 & 68 \\
& $\mathrm{~V}_{\text {sw }}\left(\mathrm{m}^{3} / \mathrm{h}\right)$ & $9.55 \times 10^{-5}$ & $6.15 \times 10^{-5}$ & $4.4 \times 10^{-5}$ & $9.41 \times 10^{-6}$ \\
& $\mathrm{Q}_{\text {cool }}(\mathrm{kcal} / \mathrm{h})$ & $4,637.52$ & $4,266.38$ & $3,968.08$ & $1,272.94$ \\
& $\mathrm{~V}_{\text {boat }}(\mathrm{m} / \mathrm{s})$ & 1.72 & 1.78 & 1.84 & 1.88 \\
2 & $\mathrm{~T}_{\text {in }}\left({ }^{\circ} \mathrm{C}\right)$ & 29 & 29 & 29 & 29 \\
& $\mathrm{~T}_{\text {out }}\left({ }^{\circ} \mathrm{C}\right)$ & 43.5 & 48 & 55.5 & 69 \\
& $\mathrm{~V}_{\text {sw }}\left(\mathrm{m}^{3} / \mathrm{h}\right)$ & $9.33 \times 10^{-5}$ & $6.25 \times 10^{-5}$ & $4.35 \times 10^{-5}$ & $9.4 \times 10^{-6}$ \\
& $\mathrm{Q}_{\text {cool }}(\mathrm{kcal} / \mathrm{h})$ & $4,692.5$ & 4,119 & $3,998.43$ & $1,304.19$ \\
& $\mathrm{~V}_{\text {boat }}(\mathrm{m} / \mathrm{s})$ & 1.7 & 1.79 & 1.84 & 1.88 \\
& $\mathrm{~T}_{\text {in }}\left({ }^{\circ} \mathrm{C}\right)$ & 29 & 29 & 29 & 29 \\
& $\mathrm{~T}_{\text {out }}\left({ }^{\circ} \mathrm{C}\right)$ & 43.25 & 48.5 & 55.25 & 68.5 \\
& $\mathrm{~V}_{\text {sw }}\left(\mathrm{m}^{3} / \mathrm{h}\right)$ & $9.44 \times 10^{-5}$ & $9.2 \times 10^{-5}$ & $4.38 \times 10^{-5}$ & $9.41 \times 10^{-6}$ \\
& $\mathrm{Q}_{\text {cool }}(\mathrm{kcal} / \mathrm{h})$ & $4,665.01$ & $4,192.67$ & $3,983.25$ & $1,288.57$ \\
& $\mathrm{~V}_{\text {boat }}(\mathrm{m} / \mathrm{s})$ & 1.71 & 1.785 & 1.84 & 1.88 \\
\hline
\end{tabular}

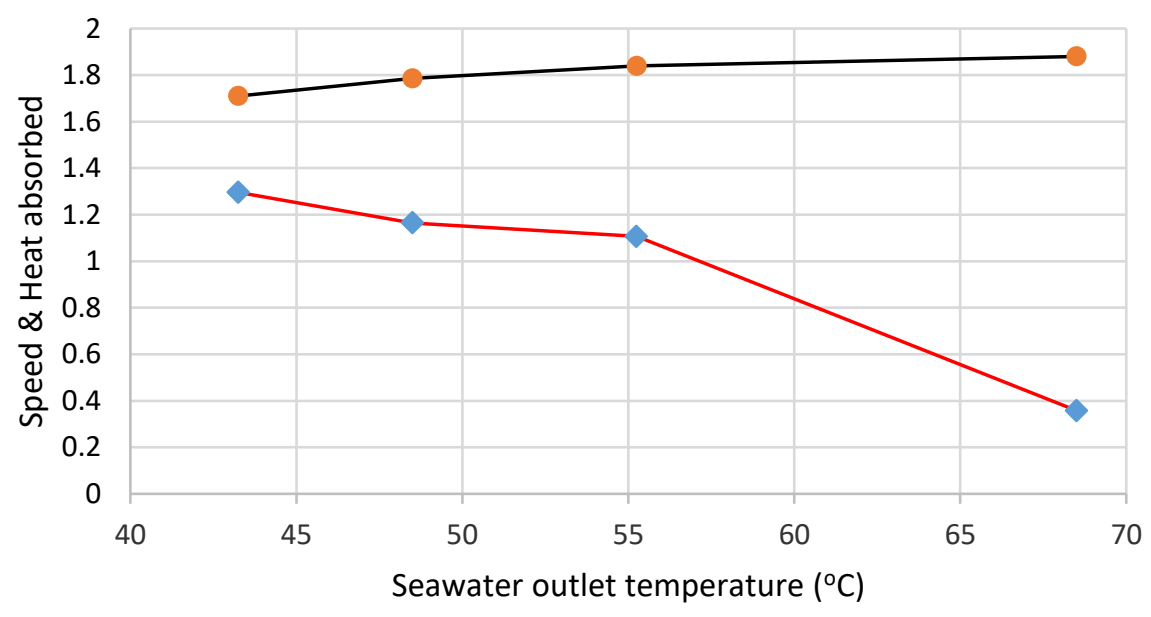

$\longrightarrow$ Heat absorbed by seawater $(\mathrm{kcal} / \mathrm{h}) \quad \longrightarrow$ Speed of boat $(\mathrm{m} / \mathrm{s})$

Figure 5. Correlation Between the Absorbed Heat by Seawater Cooling and the Speed of Fishing Boat

Based on Table 4, with valve opening $75 \%$ of seawater temperature reaches $48.5^{\circ} \mathrm{C}$. If the valve opening is reduced a little more, so that the seawater temperature is $50 \mathrm{oC}$, the fishing boat speed reaches $1.8 \mathrm{~m} / \mathrm{s}$, as shown in Figure 5 . There is an increase in the speed of $5.3 \%$ in this condition compared to existing conditions is $1.708 \mathrm{~m} / \mathrm{s}$. From Table 3 , the engine power is $7.5 \mathrm{HP}$, SFOC $195 \mathrm{~g} / \mathrm{HP} . \mathrm{h}$ and the density of diesel fuel is $840 \mathrm{~kg} / \mathrm{m}^{3}$, so that fuel consumption per $10 \mathrm{~km}$ distance can be obtained as follows: 
Existing fuel consumption:

$$
\frac{\operatorname{SFOC}\left(\frac{g r}{H P . h r}\right) \times H P(H P) \times S(m)}{3600 \times V_{s}\left(\frac{m}{S}\right) \times \rho_{\text {fuel }}}=\frac{195 \times 7.5 \times 10000}{3600 \times 1.708 \times 840}=2.832 \text { litre }
$$

Fuel consumption at $1.8 \mathrm{~m} / \mathrm{s}$ :

$$
\frac{195 \times 7.5 \times 10000}{3600 \times 1.8 \times 840}=2.687 \text { litre }
$$

Therefore the maximum fuel consumption savings on the existing cooling system with the addition of a valve is only $5.1 \%$. In this condition, the cooling system still absorbs excessive heat from the engine. As a solution to this problem, the existing seawater cooling system must be modified to an indirect seawater cooling system, as shown in Figure 6 . With this system, the temperature of freshwater in the hopper can be maintained at a temperature of $80^{\circ} \mathrm{C}$, and the seawater temperature as a freshwater cooler remains maintained at $50^{\circ} \mathrm{C}$.

Following the experiments on a direct seawater cooling system, the speed of a fishing boat increased to $1.887 \mathrm{~m} / \mathrm{s}$ at a valve opening of $25 \%$. At this condition, the temperature of the seawater reached $68.5^{\circ} \mathrm{C}$. The fuel consumption reached $2.578 \mathrm{~m} / \mathrm{s}$ and fuel savings of $9 \%$. For experiments at even higher temperatures were not conducted due to the risk of deposition of salt and lime.

Therefore, the prediction of valve openings and boat speed at the seawater temperature of $80^{\circ} \mathrm{C}$ was predicted based on the trendline equation in Ms. Excel. The freshwater temperature in the hopper of $80^{\circ} \mathrm{C}$ can be achieved with a valve opening of $13 \%$. The advantage gained by conducting this method is that the fishing boat's speed may increase to $1.95 \mathrm{~m} / \mathrm{s}$ (14\%) and fuel savings of $12.3 \%$.

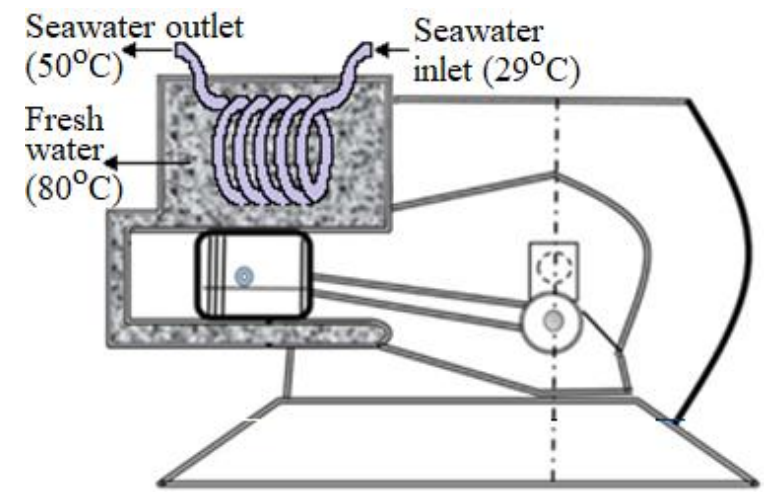

Figure 6. An Indirect Seawater Cooling System That Is Proposed To Change The Seawater Cooling System Used On A Traditional Fishing Boat

\section{Conclusion}

Based on the results of the experiments being conducted, the following conclusions can be drawn. The use of a hopper cooling system modification on a traditional fishing boat resulted in an excessive cooling process. Optimum performance improvement of the existing hopper cooling system on fishing boats cannot be obtained due to the limited operational temperature of sea water as a cooling medium. When the outlet sea water temperature is $50^{\circ} \mathrm{C}$, traditional fishermen get some benefits in the form of an increase in speed of $5.3 \%$ and fuel savings of $5.1 \%$. Therefore, the existing seawater cooling system must be modified to an indirect seawater cooling system. This re-modification allows the temperature of fresh water in the hopper to be maintained at a temperature of $80^{\circ} \mathrm{C}$, so that the speed of fishing boat may increase by $14 \%$, with a fuel savings of $12.3 \%$.

\section{References}

[1] J. F. Muir, "Fuel and energy use in the fisheries sector - approaches, inventories and strategic implications," Rome, 2015.

[2] S. Nitonye, "Design Calculations for The Cooling Water System of A Tug Boat," World Journal of Engineering Research and Technology, vol. 3, no. 4, pp. 9-26, 2017.

[3] A. Aijjou, L. Bahatti, and A. Raihani, "Enhanced Ship Energy Efficiency by Using Marine Box Coolers," Advances in Science, Technology and Engineering Systems Journal, vol. 3, no. 6, pp. 83-88, 2018, doi: 10.25046/aj030608.

[4] A. Młynarczak, "Box coolers as an alternative to existing cooling systems," Scientific Journals of the Maritime University of Szczecin, vol. 36, no. 108, pp. 131-136, 2013.

[5] G. Theotokatos, K. Sfakianakis, and D. Vassalos, "Investigation of ship cooling system operation for improving energy efficiency," Journal of Marine Science and Technology, vol. 22, no. 1, pp. 38-50, 2017, doi: 10.1007/s00773-0160395-9.

[6] W. A. Abdelghaffar, M. M. Osman, M. N. Saeed, A. I. Abdelfatteh, "Effects of Coolant Temperature on the Performance 
and Emissions of a Diesel Engine," in Proceedings of the ASME 2002 Internal Combustion Engine Division Spring Technical Conference. Design, Operation, and Application of Modern Internal Combustion Engines and Associated Systems, pp. 197-197, 2002.

[7] A. Rehman, R. M. Sarviya, S. Dixit, and R. K. Pandey, "Influence of coolant temperature on the performance of a four stroke spark ignition engine employing a dual circuit cooling system," Agricultural Engineering International: CIGR Journal, vol. 12, no. 1, pp. 84-90, 2010.

[8] B. S. Fengming Zhang, Shiming Xu, Dongdong Feng, Shunquan Chen, Ruxu Du, Chuangjian Su, "A low-temperature multi-effect desalination system powered by the cooling water of a diesel engine," Desalination, vol. 404, pp. 112120, doi: 10.1016/J.DESAL.2016.11.006.

[9] V. Zhukov, O. Melnik, N. Logunov, S. Chernyi, "Regulation and control in cooling systems of internal combustion engines," E3S Web of Conferences, vol. 135, 2019, doi: 10.1051/e3sconf/201913502015.

[10] V. Konoplev, V. Bogdanov, Z. Melnikov, G. Belitsky, "Prospects for development of high-temperature evaporative cooling systems of internal combustion engines with increased temperatures of the cooling body," IOP Conference Series: Materials Science and Engineering, vol. 675, 2019.

[11] G. Pramuhadi, Class Lecture, Topic: "Listrik dan Pendinginan," IPB University, 2004.

[12] S. Jafari, J. F. Dunne, M. Langari, Z. Yang, J-P. Pirault, C. A. Long, J. T. Jose, "A review of evaporative cooling system concepts for engine thermal management in motor vehicles," Proceedings of the Institution of Mechanical Engineers, Part D: Journal of Automobile Engineering, vol. 231, no. 8, pp. 1126-1143, 2017, doi: $10.1177 / 0954407016674606$.

[13] M. Elg, M. Kuosa, M. Lampinen, R. Lahdelma, P. Mäkipeska, J. Raita, Z. Guangrong, K. Tammi, "Advanced auxiliary cooling system for energy efficient ships," in 9th International Conference on Energy Efficiency in Motor Driven Systems (EEMODS'15), pp. 762-772, 2015, doi: 10.2790/903731. 